Critical Studies in Improvisation / Études critiques en improvisation, Vol. 14, Nos. 2-3

\title{
A Good Time to Plant Seed
}

\section{Dong-Won Kim}

The actual beginning of the twentieth century was in 1919, after World War I. The actual beginning of the twenty-first century will be in 2019, as it has begun with COVID-19.

- Dae-Shik Kim (Professor of Brain Science, Korea Advanced Institute of Science and Technolgoy), interview on CBS Radio, "Sisa Jockey; Jeong, Gwan-Yong," May 11, 2020. Translation by the author.

I would like to suggest that we-musicians, performers, artists, improvisers, and shamansacknowledge the ambivalence of the present moment. To be sure, the pandemic has caused a great deal of suffering. But it may also be an opportunity to stimulate our artistic immune system for the future.

l'd like to tell you a story.

Once upon a time in China, there was an old man who raised horses. He had one son whom he loved dearly. One day, his favorite horse escaped and crossed the border. His neighbours consoled him: "We are all so sorry for your loss." The old man said: "Well, we'll see if it's bad or not." A few days later, the horse came back to his ranch with a bunch of wild horses. His neighbours congratulated him: "We are so happy that your horse came back with many others." The old man said: "Well, we'll see if it's good or not." A few days later, his son fell from the horse and broke a leg. His neighbours consoled him: "We are so sorry for your son's injury." The father said: "Well, we'll see if it's bad or not." A few days later, the whole country went to war, but his son was excluded from the conscription because of his leg injury, and he went on to live a long life.

During the pandemic, the word "untact," meaning no-contact, has become a keyword in Korea that has been applied to virtually every human activity: all gigs were cancelled, venues and festivals had to be shut down, and face-to-face teaching in the classroom became very risky. As difficult as the pandemic has been, I think it is possible for positive change to come from this period. We all know that life is full of struggle. But in this time of the pandemic, 7.7 billion of us are struggling - struggling to look after ourselves, our loved ones, and each other. We do this by wearing masks and maintaining physical distancing protocols. Maybe the ethic of care that we have seen in so many places will continue after the pandemic has ended. Maybe it is a seed that will grow and bear fruit in the years to come.

Let's imagine that we are farmers who just lost this year's harvest by flood or storm. What can we do to recover the damage? The only way we can recover is to plant seed for next year's harvest. Even if the damage happened right before harvest, our only option is to start over by planting seed. We begin by choosing the best seeds. Then, we wait for the best timing, preparing the soil and optimizing our chances of a successful harvest. Only then do we plant our seeds, taking care of our plants as they grow-watering them, removing weeds, and so forth. We do not do this work alone. We can encourage each other and develop a sense of community and gratitude for the time we spend together planting seeds.

What are our seeds as improvisers? I think taking care of ourselves is one seed that we can plant and nurture during the pandemic. To shoot an arrow towards a target, we need to draw the bowstring back towards ourselves first. Maybe it's a good time to work on our own musicianship, 
our skills, our attitude, our philosophy—what Western colleagues might call "woodshedding." In so doing, we can explore and develop new approaches to our instrument, to our collaborators, to ourselves, to our audience, and to the world. We can use this time to experiment and reexamine our improvisatory practice from different angles. One of the great joys of improvising is the process of co-creation and discovery through musical dialogue with collaborators. In the absence of improvising partners, we can develop and enhance our own musical vocabulary in anticipation of making our future musical conversations richer and more varied. During this difficult time, we have an opportunity to treat our own musicianship as a seed that we nurture in order to prepare for the future.

Improvisation fosters community and friendship, and these things need to be cared for too. We need to unite in solidarity to support one another as we look for solutions, push the decisionmakers, and advocate for policy changes--long-term systemic fixes that enhance sustainable musicking. We should not wait or hope for things to return to the way they were before the pandemic. It's time for humanity to engage in a collective improvisation in order to bring about lasting change for ourselves and for future generations. Let's listen to one another and encourage one another, and in so doing achieve something new together.

During the pandemic, many creative practitioners have moved their activities online. Web-based platforms for networked musical performance can be useful, but they are a double-edged sword. If we are not careful, they will harm us. In South Korea, most performances, lectures, performing arts competitions, and academic conferences that have taken place during the pandemic have been delivered online through platforms such as YouTube and various social networking services. But these events are often poorly attended. Even if people are keen to watch an online performance, there are simply too many distractions and excuses to attract a large and attentive audience.

Going forward, I think we should be careful about the extent to which we move our music online. If we rely solely on the Internet to communicate with the public, we will lose their attention. I've been using online technologies for music education and performance for over two decades, and although online platforms for networked music making and music consumption have been tremendously helpful during the pandemic, they shouldn't be the only option for our artistic activities. We need to find ways to continue to engage with the public and with our communities "in real life" as much as possible. That may mean playing music while wearing masks or hosting outdoor events at which audience members stay two meters apart while enjoying the performance. We can perform in public spaces, in parks, on street corners, or in the forest.

The move online and outdoors has meant decreased income for the vast majority of musicians in the world. This is why we need to unite in solidarity and advocate for policies that will benefit musicians and humanity more generally. We must put pressure on our elected officials to ensure that everyone earns a living wage, especially during financially precarious times such as these. We need to work together to end neoliberal and disaster capitalist policies that concentrate wealth in the hands of an ever-shrinking elite. The pandemic has made clear the need for the rich to pay more taxes for the benefit of society as a whole. In return, we will continue to bring music and joy to the public as we've been doing for generations.

In conclusion, I would like to return to the story of the old man. He was wise enough to see the ambivalence of life; so it is with the pandemic. Despite the current challenges, the present moment represents an opportunity for us to enter the twenty-first century in new ways. Let's start over. Let's be the improvisers of the twenty-first century. It's a good time to plant the seed. 